\title{
Fenomena Swafoto dan Pengaruhnya Terhadap Budaya Visual pada Estetika Interior Ruang Komersial
}

\author{
Ira Audia Agustina ${ }^{1}$, Yongkie Angkawijaya ${ }^{2}$ \\ ${ }^{1}$ Dosen Interior ITK Binus Malang, ${ }^{2}$ Dosen DKV ITK Binus Malang \\ 1ira.agustina@binus.edu, ${ }^{2}$ yongkie.angkawijaya@binus.edu
}

\begin{abstract}
ABSTRAK
Penggabungan teknologi komunikasi dan kamera yang terdapat pada telepon seluler pintar menciptakan fenomena baru, yaitu perilaku swafoto dengan dampak amat luas: cakupannya lintas generasi, sosial-budaya, dan strata ekonomi (Kavitha Bhuvaneswari, 2016). Implikasi dari fenomena ini adalah perubahan prioritas dalam mendesain dan mempromosikan berbagai jenis ruang komersial publik, dari yang semula berorientasi pada kenyamanan fisik dan fisiologis pengguna, kini mulai lebih memprioritaskan keindahan dan keunikan visual ruang agar dapat menjadi destinasi wisata swafoto yang 'instagrammable'. Penelitian ini bertujuan untuk mengetahui seberapa jauh fenomena swafoto mempengaruhi perancangan desain interior pada ruang komersial, dan bagaimana fenomena ini berpengaruh terhadap tingkat kesadaran masyarakat terhadap estetika visual pada desain interior ruang komersial. Penelitian ini menggunakan metode exploratory research, dengan menggunakan Studi literatur, teknik wawancara terhadap pengguna ruang dan desainer arsitektur \& interior ruang publik, observasi lapangan di beberapa lokasi destinasi wisata swafoto area Malang yang terbagi kedalam tiga kategori: Resto/Cafe, area wisata keluarga, dan Hotel/ Villa, beserta kuisioner random sampling terhadap kedua kelompok responden tersebut. Hasil yang didapatkan adalah keunikan visual ruang menjadi salah satu prioritas dalam mengkonsep perancangan ruang komersial yang mentarget pengguna dengan rentang usia 13-40 tahun, dengan tujuan agar dapat menjadi destinasi wisata swafoto. Penelitian ini juga menunjukkan bahwa fenomena swafoto ini membawa dampak positif terutama pada generasi muda yang semakin memiliki kesadaran terhadap estetika visual yang ada di lingkungan sekelilingnya dibandingkan generasi sebelumnya, dan memiliki dampak lanjutan naiknya level kebudayaan visual pada masyarakat. Fenomena ini harus dapat direspons dengan baik dan optimal oleh semua kelompok desainer; dari interior, arsitektur, grafis hingga produk, untuk dapat memberikan rancangan yang tidak hanya menarik secara visual, namun juga mampu memberikan pemahaman budaya, lingkungan, dan estetika yang benar kepada masyarakat.
\end{abstract}

Kata kunci: swafoto; budaya visual; estetika; interior; ruang komersial

\section{ABSTRACT}

The integration between camera and communication technology inside the smartphone, creating a new phenomenon in society, that is 'selfie', which has a broad impact: the phenomenon coverage across generations, socio-culture, and economical level. This phenomenon implies priority changes in designing and promoting various types of commercial public spaces, and how this phenomenon affecting public awareness level of visual aesthetic in commercial interior design. This research conducted with exploratory research, by literature study, using interviewing techniques toward place users and architecture \& interior designer of commercial public area, field observation in several selfie travel destination in Malang area divided into 3 category: Cafe/Restaurants, family tourism destination, and villa/ hotels, and random sampling questionnare towards both group respondents. The result obtained that place's visual uniqueness become one of the top priority in concepting commercial space design with the target user in age range within 13-40 years old, aiming to become a tourist's selfie travel destination. This research also shows that selfie phenomenon has a positive impact specially on young generation who having an increasing visual awareness of aesthetics in their surrounding environment than the older generations, and further impacting in increased level of visual culture in society. This phenomenon should be responded well and optimally by all designer category: from interior, 
Ira Audia Agustina, Yongkie Angkawijaya

Fenomena Swafoto dan Pengaruhnya Terhadap Budaya Visual pada Estetika Interior Ruang Komersial

architecture, graphical to product designer who would provide a design that is not only visually appealing, but also be able to give a better understanding of culture, environment, and aesthetics to society.

Keyword: selfie; visual culture; aesthetic; interior; commercial space

\section{PENDAHULUAN}

Lajunya perkembangan teknologi pada abad 21 hingga kini memberikan dampak yang amat signifikan pada perubahan karakteristik sosial perilaku masyarakat, dimana salah satu teknologi yang berperan dalam perubahan tersebut adalah kemunculan gawai (mobile phone) dan penyematan teknologi kamera didalamnya. Penggabungan kedua teknologi tersebut memunculkan fenomena perilaku swafoto pada masyarakat dari lintas generasi, sosial-budaya, dan strata ekonomi. Penggemar swafoto amatlah sangat beragam, mulai dari rakyat biasa hingga selebriti, dari pejabat tinggi kenegaraan hingga astronot yang sedang melakukan perjalanan luar angkasa (Tanasa, 2015).

Pada studi yang dilakukan Okabe (2005) pada masyarakat Jepang, menunjukkan bahwa semenjak diperkenalkannya "sha-mail” (photo mail) oleh provider J-Phone pada November 2000, telah merubah cara komunikasi masyarakat Jepang, dimana penggunaan kamera gawai mencapai lebih dari 60\% penggunaan gawai secara umum. Penggunaannya pun mulai menggantikan kamera konvensional dengan lebih dari 50\% responden menyimpan kembali foto-foto mereka ke dalam PC (Okabe \& Ito, 2005). Perubahan kultur dalam komunikasi digital ini juga merambah ke berbagai jenis tanda-tanda dalam sistem bahasa, dimana suatu bentuk komunikasi dengan menyertakan gambar visual yang unik dan tematik telah menjadi suatu bentuk komunikasi yang lazim, terutama dengan kemunculan meme, stickers, emoticons, dan berbagai simbol bahasa visual lainnya.

Fenomena swafoto ini telah menjadi daya tarik tersendiri di bidang akademis dan telah banyak diteliti dari sudut pandang psikologis, budaya, maupun manajemen. Salah satu penelitian yang berfokus pada penggiat swafoto dengan rentang usia 12-17 tahun berpendapat bahwa swafoto adalah suatu bentuk social presence atau bukti kehadiran sosial dan sarana pembentukan identitas, dimana remaja dengan rentang usia 12-17 tahun memiliki tingkat privasi yang lebih tinggi saat melakukan swafoto (Ardiyanti, Hadyanto, Krislamawaty, \& Irwansyah, 2018). Studi lain yang dilakukan oleh Tysna (dalam Ardiyanti et al., 2018) mengungkapkan swafoto sebagai suatu bentuk hubungan interaksi simbolik yang memfokuskan pada konsep diri: suatu bentuk persepsi pribadi yang cenderung stabil dan dianggapnya diyakini pula oleh orang lain.

Berdasarkan motivasi, penelitian terhadap fenomena swafoto dapat dibagi menjadi beberapa poin umum: Pertama oleh Van Hose (et al, 2004 dalam Okabe \& Ito, 2005) mengkategorikan kedalam tiga bagian berdasarkan motif tingkat tinggi: relasi sosial, ekspresi diri, dan presentasi diri. Dan kedua adalah dari Okabe (2005) yang menganalisa bahwa kamera gawai dapat digunakan sebagai visual diary yang dapat lebih memiliki sudut pandang yang intim, santai dan personal, yang diunggah dan dibagikan ke dalam circle yang lebih privat. Motivasi lainnya dari swafoto adalah sebagai suatu bentuk eksistensi diri pengguna, agar tidak dianggap ketinggalan zaman dan mendapatkan pengakuan dari orang lain terhadap diri pengguna, melalui berbagai respon yang didapatkan dari mengunggah swafoto pribadi kedalam akun media sosialnya (Ajeng \& Oktavia, 2018).

Analisa mengenai dampak negatif swafoto juga dapat diringkas kedalam poin-poin berikut ini:

- Isu yang paling menonjol dari fenomena swafoto ini adalah mengenai isu keamanan identitas, privasi, dan pengawasan (Iqani, 2016 dalam Ardiyanti et al., 2018). Dengan 


\section{Di|Fink}

Vol. 4, No. 1, Juni 2019, pISSN 2527-2853, eISSN 2549-2985

mengunggah di media sosial aktifitas harian seseorang, maka orang lain dapat menganalisa secara langsung rutinitas si pengunggah yang dapat dipergunakan untuk hal-hal yang buruk. Demikian pula dengan kebiasaan mengunggah swafoto di lokasi bencana, yang dianggap tidak etis dan pernah menjadi isu besar saat terjadi bencana gempa tektonik Jogja di tahun 2006, dimana banyak orang dari luar daerah terdampak bencana yang berbondongbondong masuk ke Jogja hanya untuk berswafoto di antara reruntuhan bangunan.

- $\quad$ Penguatan ego self-narcissism. Berdasarkan Najib, Sugiarto, \& Erawati, (2018):

"Swafoto yang bersifat narsistik adalah foto diri yang dibagikan melalui media sosial sedikitnya dua foto per minggu, dengan memiliki kepercayaan diri secara berlebihan, merasa unggul dengan maksud mengeksplore diri ke publik, guna mendapatkan perhatian yang selalu mengejar orang lain”.

Pengunggahan swafoto dengan frekwensi yang terlalu sering di media sosial juga dianggap mengganggu, dikarenakan memberikan informasi yang terlalu banyak hingga dapat membuat warganet menjadi jenuh (Fikrie, dalam Ardiyanti et al., 2018).

Sedangkan hal positif baru yang didapatkan dari fenomena swafoto ini pun banyak dan beragam, salah satunya adalah dengan memanfaatkannya sebagai suatu bentuk ekspresi feminitas perempuan (Mecca, 2019); sebagai suatu bentuk alternatif promosi destinasi wisata (Wanagiri, Widyastuti, Luh, Prawitha, \& Suyasa, 2018) (Yuniarso, Wiyana, Zulkarnain, \& Khrisnanto, 2018); sebagai suatu citra destinasi wisata (Cahyanti \& Anjaningrum, 2017); dan sebagai suatu bentuk dokumentasi fotografi pribadi dalam kehidupan sehari-hari oleh pengguna (Okabe \& Ito, 2005) dikarenakan kemudahan pemakaiannya apabila dibandingkan dengan kamera konvensional.

Mengenai swafoto pada area wisata/ publik, hal ini juga tidak terlepas dari perubahan gaya hidup generasi muda yang kini gemar melakukan travelling. Menurut Badan Pusat Statistik (BPS), terdapat peningkatan jumlah mobilitas masyarakat keluar negeri untuk travelling pada Februari 2013 sebesar 16,295 yang didominasi oleh kaum muda, dimana hal ini mengindikasikan travelling sebagai sesuatu yang familiar dilakukan oleh generasi masa kini. Wisawan juga cenderung menjatuhkan pilihan pada area wisata yang menarik, murah, atau khusus, dikarenakan jenis wisata seperti ini dapat memberikan suatu pengalaman baru dan memori yang berkesan (Cahyanti \& Anjaningrum, 2017).

Melalui berbagai macam kajian penelitian diatas, dapat terlihat munculnya keterhubungan antara fenomena swafoto menggunakan kamera gawai dengan meningkatnya budaya visual sebagai salah satu bentuk komunikasi relasi sosial dan eksistensi diri. Para pelaku bisnis pun tampaknya telah menanggapi fenomena tersebut sebagai alternatif media promosi bisnisnya, terutama yang berkaitan dengan bisnis ramah-tamah (hospitality) yang berfokus pada pengalaman pengunjung. Namun dalam berbagai penelitian tersebut masih belum didapatkan data dan keterhubungan secara langsung antara fenomena swafoto terhadap proses dan aplikasi perancangan interior ruang komersial. Konteks inilah yang menjadi landasan pemikiran dalam penelitian ini. Pada penelitian ini bermaksud untuk menganalisa permasalahan sebagai berikut:

a. Seberapa jauh fenomena swafoto ini mempengaruhi desainer interior/arsitektur dalam merancang suatu area publik komersial?

b. Seberapa jauh fenomena swafoto mempengaruhi masyarakat dalam memilih lokasi wisata?

c. Model interior ruang publik dengan karakteristik visual seperti apa yang paling diminati pengunjung untuk ber-swafoto? 
Batasan pada penelitian ini adalah area penelitian berada di area Malang Kota, dengan konteks ruang publik yang dimaksud adalah area yang digunakan secara komersial (pengunjung harus membayar/membeli sesuatu untuk dapat masuk ke lokasi). Konteks penggunaan swafoto dalam penelitian ini dibatasi pada penggunaannya yang menggunakan kamera gawai, dengan unsur visual yang tidak berfokus pada tampilan pribadi (swafoto narsistik) melainkan lebih pada menunjukkan suasana ruang interior pada suatu area komersial publik. Untuk batasan area lokasi penelitian tidak dibatasi. Profesional yang disurvey pada penelitian ini adalah yang telah merancang desain interior ruang komersial publik selama kurun 10 tahun terakhir (2019-2009). Pengunjung yang disurvey dalam penelitian ini adalah dari generasi Millenial dan Generasi Z yang sering bepergian ke tempat-tempat wisata, dan sering mengunggah swafoto pribadi pada akun media sosial mereka.

\section{METODE PENELITIAN}

Penelitian ini menggunakan metode riset exploratory, dengan pertimbangan bahwa fenomena swafoto dalam masyarakat ini tergolong fenomena baru yang muncul 10-15 tahun terakhir seiring dengan perkembangan teknologi, dimana hubungan antara fenomena swafoto dan pengaruhnya terhadap budaya visual dalam masyarakat memerlukan tidak hanya data kualitatif, melainkan juga data kuantitatif sehingga penelitian ini dapat membahas fenomena tersebut secara menyeluruh dan mendalam, juga untuk mendapatkan wawasan yang signifikan bagi pengembangan hipotesa penelitian. Metode exploratory menggunakan 2 teknik pengumpulan data.

\section{A. Tahapan Primer}

Pada penelitian ini menggunakan beberapa teknik pengambilan data yaitu:

1. Interview

Interview dilakukan pada 2 kelompok, yaitu kelompok pengguna ruang dan kelompok perancang ruang komersial publik. Kelompok pengguna ruang terdiri dari 50 responden dengan rentang usia 13-40 tahun yang sering bepergian untuk berwisata. Rentang usia tersebut untuk mengakomodasi responden generasi Millenial (kelahiran 1980-2000) dan generasi Z (kelahiran 2000 - sekarang) (Kavitha Bhuvaneswari, 2016) yang dianggap telah akrab dengan teknologi kamera pada smartphone.

2. Observasi lapangan

Observasi lapangan dilakukan di 3 lokasi ruang komersial Malang yang dipilih berdasarkan tingkat popularitasnya di media sosial. Ketiga lokasi ruang komersial tersebut dibagi berdasarkan jenis Pada penelitian ini, media sosial yang menjadi acuan adalah Instagram (IG), dan forum internet. dengan pertimbangan bahwa IG adalah media sosial arus utama yang berplatform visual (fotografi). Pencarian didapatkan dengan menggunakan tagar (\#)exploremalang. Dari IG \& forum internet didapatkan lokasi ruang komersial terpilih yaitu:

a). Kampung Heritage, Kajoetangan

b). Golden Heritage, Tidar

c). Hotel Tugu, Kota Malang

Hal yang diobservasi adalah: perilaku pengunjung terhadap ruang, termasuk di dalamnya adalah elemen-elemen pembentuk ruang.

3. Survey

Kuisioner dilakukan dengan menggunakan random sampling yang disebarkan secara online. Pembatasan responden berdasarkan usia (13-40 tahun), penghobi wisata dan swafoto. Responden dibagi menjadi dua kelompok, yaitu kelompok profesional desainer interior dan 
arsitektur (Kelompok A); dan pengunjung di lokasi (Kelompok B). Konteks pertanyaan pada kedua kelompok tersebut adalah sebagai berikut:

$>$ Kelompok A: mengetahui seberapa jauh desainer mempertimbangkan aspek swafoto pengunjung dalam perancangan interiornya, dan seberapa jauh desainer mengaplikasikan aspek tersebut dalam perancangannya.

$>$ Kelompok B: mengetahui seberapa jauh estetika visual ruang suatu lokasi mempengaruhi keputusan pengunjung untuk datang ke lokasi tersebut dan ber-swafoto. Mengetahui seberapa jauh pengunjung dapat memilih atas kesadaran sendiri lokasi-lokasi yang menarik untuk ber-swafoto dan diunggah ke akun media sosial mereka.

\section{B. Tahapan Sekunder}

Pada tahapan ini, pengambilan data menggunakan beberapa teknik sebagai berikut:

1. Riset Literatur

Studi literatur dilakukan untuk mendapatkan landasan teori mengenai: sudut pandang psikologis dari fenomena swafoto di indonesia, dampak wisata swafoto terhadap peningkatan jumlah pengunjung suatu ruang komersial, dan literatur lainnya yang mendukung.

2. Studi Kasus

Studi kasus dilaksanakan pada obyek-obyek yang terpilih berdasarkan tingkat popularitas di media sosial Instagram, sesuai dengan tahapan observasi lapangan. Jenis obyek penelitian juga dibuat beragam, yang terbagi menjadi 3 jenis area komersial yaitu: lokasi wisata keluarga, lokasi third place (Cafe/Resto), dan Villa/Resto.

Metode analisa menggunakan deskriptif-analitis dengan memberikan gambaran secara deskriptif mengenai korelasi antara fenomena swafoto dengan tingkat kesadaran budaya visual di masyarakat. Analisa dilakukan dengan menanyakan kepada responden pengguna ruang motivasi pemilihan destinasi , seberapa banyak responden melakukan swafoto pada suatu area komersial publik, dan area seperti apa yang dipilih oleh pengunjung untuk menjadi latar swafoto mereka.

\section{HASIL PENELITIAN DAN PEMBAHASAN}

Dalam dunia digital dan perkembangan teknologi komunikasi saat ini, bahasa visual telah menjadi sesuatu yang sangat diandalkan, yang dianggap mampu melengkapi bentuk komunikasi tulisan biasa. Dunia visual memberikan suatu pengalaman baru yang penuh kejutan (Ismanto, 2018), dimana "Jagat raya maya itu dianggap lebih menyenangkan dibandingkan dunia nyata itu sendiri” (Djuli, dalam Ismanto, 2018). Komunikasi secara visual, entah itu melalui tanda-tanda visual yang terdapat pada emoticons maupun karikatur sticker pada media komunikasi digital; ataupun pada kemunculan fenomena meme, memberikan suatu bentuk keterwakilan ekspresi bahasa yang lebih menarik, dan menyenangkan. Oleh karena itu Senft (2015, dalam Ismanto, 2018) menganggap hal itu dapat menjadi salah satu alasan aktifitas swafoto dapat berfungsi sebagai obyek politisasi wacana tentang bagaimana orang terwakili, dan sebagai suatu dokumen terhadap berbagai memori kisah perilaku mereka. Oleh Iswanto (2015), budaya swafoto pada masyarakat urban dapat berfungsi sebagai berikut:

1. Budaya swafoto dapat menjadi moral panic

2. Budaya swafoto dapat pula menandakan keterbukaan diri pengguna dimana hal ini akan menyebabkan semakin eratnya interaksi dan komunikasi yang akan terjalin dengan pengguna lain di media sosial, dan dalam beberapa kasus, hal ini akan berlanjut di dunia nyata. Sehingga, pengguna dapat merasakan semakin luasnya jaringan sosial yang dimiliki. 
3. Budaya swafoto juga dapat menjadi suatu bentuk narsisme digital, dimana pengguna lebih dimotivasi oleh keinginan untuk menarik kesan pengguna lain dalam jaringan pertamanan di media sosial mereka. Hal ini mengakibatkan pengguna memiliki kecenderungan untuk selalu menampilkan yang terbaik, hingga melebihi batas kemampuan sebenarnya dari pengguna. Oleh para psikolog, kecenderungan seperti ini sudah dianggap sebagai suatu penyakit gangguan jiwa.

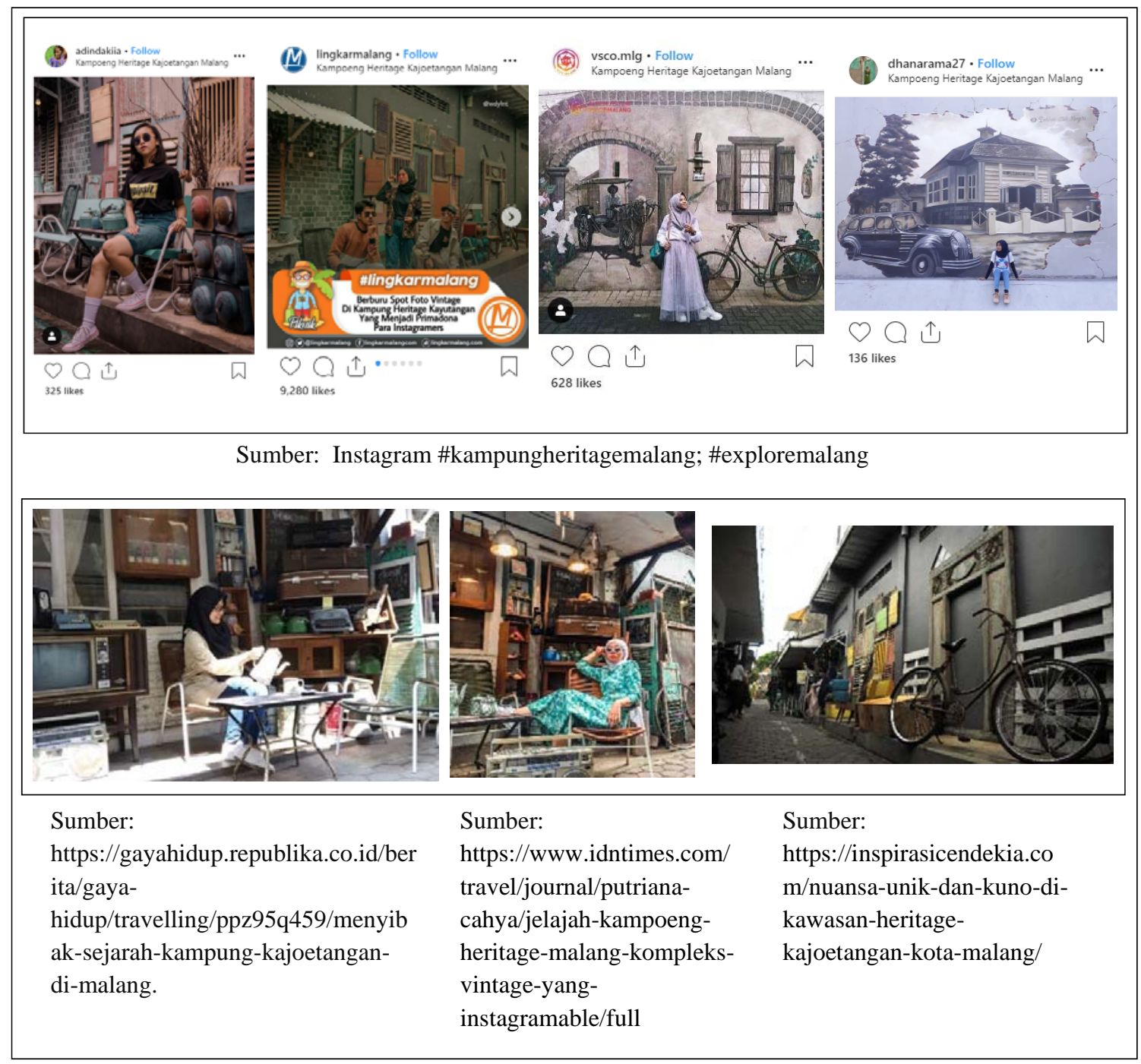

Gambar 1. Kampung Heritage Kayutangan

Sumber: tertera dalam gambar (2019)

Kampung Heritage Kayutangan berlokasi di wilayah Kayutangan (Kajoetangan), Malang Kota. Kawasan ini menjadi area bersejarah peninggalan kolonial Belanda yang oleh pemerintah sengaja dipertahankan bentuk aslinya (Gambar 1). Kampoeng Heritage Kayutangan itu sendiri baru diresmikan oleh Pemerintah Kota Malang sebagai kampung wisata tematik Kota Malang pada bulan April 2018. Konsep Kampung Heritage ini sendiri adalah mengusung suasana masa lampau, sehingga perancangan estetika ruangnya pun menampilkan benda-benda klasik pada jaman tahun 70’-80’ an. 
Pada swafoto yang dilakukan di area Kampung Heritage Kayutangan, pada analisa di instagram dengan hastag \#kampungheritagemalang, nampak bahwa pengunjung lebih menyukai swafoto yang menonjolkan estetika visual ruang, dimana banyak juga yang tidak menampakkan diri pribadi, melainkan lebih mengabadikan penonjolan estetika area kampung wisata. Motivasi pengunjung dalam berswafoto di area ini lebih ke arah eksistensi diri, dimana pengunjung ingin memamerkan bukti bahwa mereka telah berkunjung ke lokasi wisata tersebut, dan mengabadikan momen estetika visual area tersebut kedalam bentuk swafoto. Di area ini pengunjung juga berusaha mencari area yang unik dan menarik untuk berswafoto, dimana kemudahan pemakaian kamera gawai memungkinkan pengunjung untuk lebih bebas untuk berpose, melakukan trial-and-error pengambilan gambar, dan mencoba sudut-sudut pengambilan gambar yang tidak biasa.

Saat berada di Kampung Heritage, pengunjung yang kebanyakan didominasi oleh anak muda usia 15-30 tahun merasakan suasana masa lalu yang terdapat pada Kampung Heritage sebagai sesuatu yang baru, menarik, dan menciptakan kesan mendalam bagi pengunjung. Style retro pada arsitektural, interior dan pernak-pernik barang di lokasi kampung wisata oleh beberapa pengunjung dianggap mampu memberikan inspirasi dan memunculkan kesukaan baru pada benda-benda dengan desain retro. Berdasarkan observasi, peneliti juga menemui ada beberapa pengunjung yang sengaja menggunakan fashion retro, untuk mendapatkan hasil foto yang serasi dengan konsep visual ruang pada Kampung Heritage. Hal ini menunjukkan bahwa beberapa pengunjung telah mempersiapkan diri untuk melakukan swafoto di area tersebut.

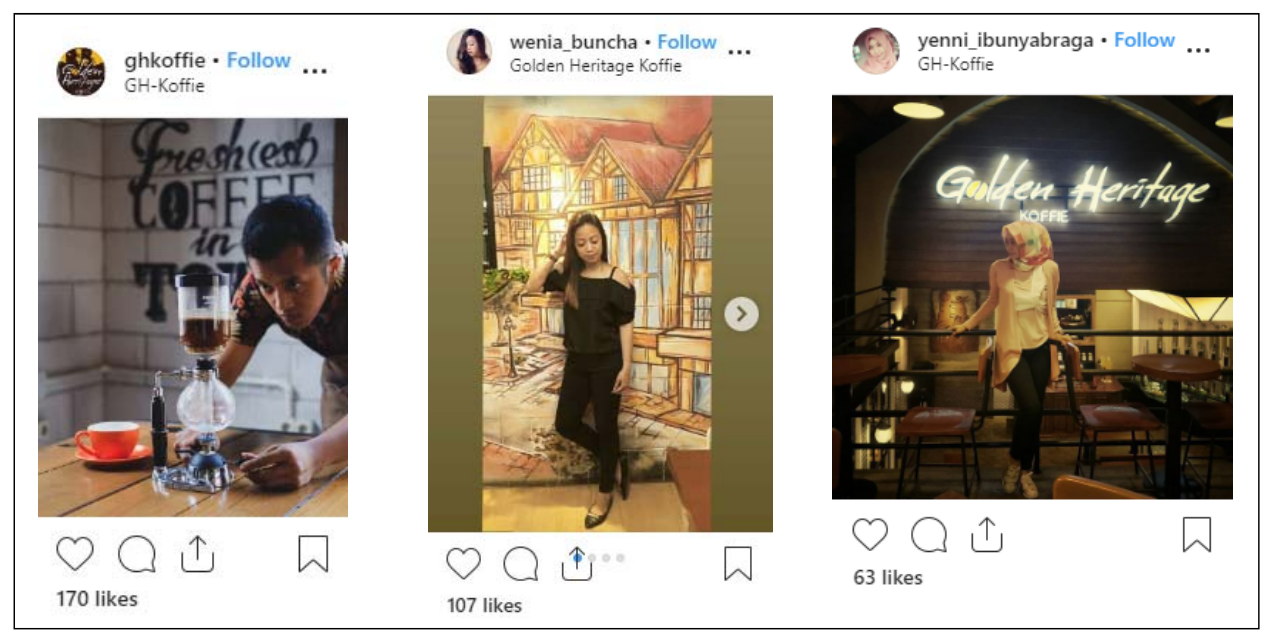

Gambar 2. Golden Heritage, Tidar

Sumber: Instagram \#goldengeritagekoffie; \#exploremalang (2019)

Golden Heritage Koffie ini adalah sebuah coffee shop yang terletak di Jl. Raya Tidar No.36, Malang. Coffee shop ini berawal dari sebuah pabrik kopi Golden Heritage di daerah Dampit yang ingin mengembangkan bisnis usahanya dengan membuka sebuah tempat dimana pengunjung dapat langsung menikmati kopi yang dihasilkan oleh pabrik ini secara langsung. Berdasarkan latar belakang tersebut, coffee shop ini memiliki desain menyerupai pabrik kopi, sehingga membuat kesan pengunjung berada langsung di dalam pabriknya konsep ruangan dalam coffee shop ini (Gambar 2). Di dalamnya terdapat mesin-mesin roasting kopi yang sengaja diletakkan di bagian depan, untuk lebih memperkuat kesan pengunjung sedang berada di dalam sebuah pabrik kopi (Kurniawan, 2018). Coffee shop adalah tempat yang menjadi 
sebuah third place, atau lokasi ketiga dimana orang-orang akan banyak menghabiskan waktu dalam hidupnya, selain rumah dan kantor (Hidalgo \& Hernández, 2001).

Pada jenis area komersial untuk makanan/minuman, pengunjung selain mencari lokasi untuk berswafoto, biasanya memiliki kebiasaan pula untuk mengabadikan visual makanan dan minuman yang tersaji, dan mengunggah di media sosial dengan menyertakan keterangan lokasi. Oleh karena itu, cofee shop atau restoran yang memiliki target pengunjung adalah anak muda usia 18-25 tahun, biasanya juga mengatur komposisi visual makanan yang mereka sajikan, agar dapat indah secara estetis saat difoto oleh pengunjung, dan dapat menjadi alternatif promosi gratis bagi cofee shop tersebut. di lokasi ini, pengunjung yang datang rata-rata berpasangan, atau bergerombol dengan rekan-rekannya. Motivasi pengunjung yang berswafoto di lokasi ini selain untuk mengabadikan keunikan coffee shop ini, juga untuk mengabadikan momen saat mereka berkumpul bersama rekan-rekan mereka di cofee shop tersebut.

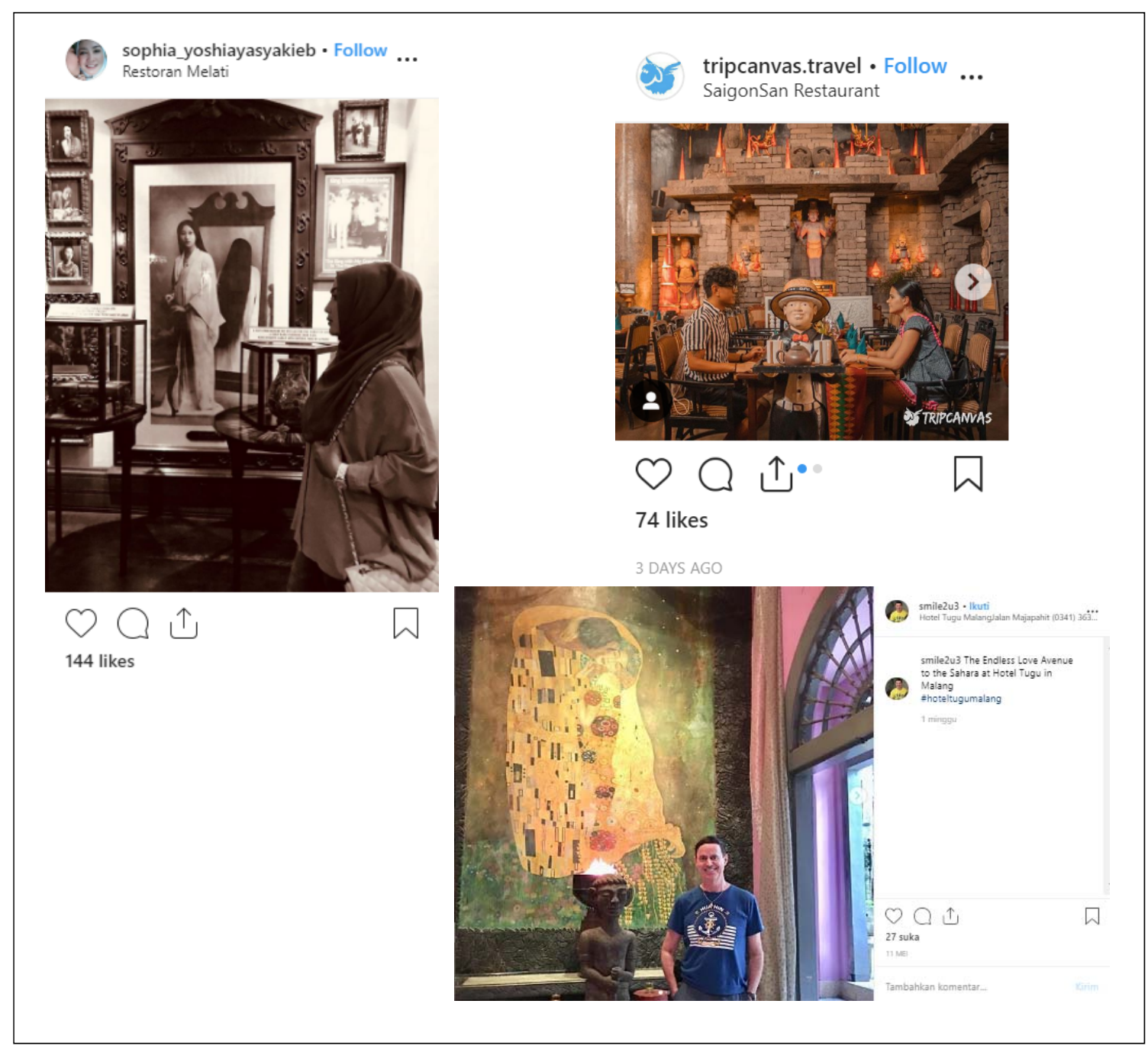

Gambar 3. Hotel Tugu, Malang Kota

Sumber: Instagram \#hoteltugumalang; \#exploremalang (2019) 


\section{Di|Fink}

Vol. 4, No. 1, Juni 2019, pISSN 2527-2853, eISSN 2549-2985

Pada lokasi obyek obervasi dan studi kasus ketiga, adalah Hotel Tugu Malang, yang beralamat di Jl. Tugu 3 depan Alun-alun Tugu, Malang Kota. Dikarenakan lokasi hotel Tugu yang strategis dengan konsep heritage yang kuat, hotel ini menjadi salah satu bangunan ikonik di Malang. Keunikan dari Hotel Tugu ini adalah pengunjung selain dapat menginap di hotel ini, juga diberikan tour gratis tentang beragam artifak-artifak klasik dan bersejarah yang menjadi koleksi dari hotel ini. Oleh karena itu, hotel ini menjadi tempat rujuan utama para turis asing yang ingin mengenal sejarah kota Malang. Hotel sekaligus museum ini memiliki artifak bersejarah yang dikoleksi oleh Anhar Sejadibrata, pendiri Tugu Group, yang merupakan kerabat dekat Oey Tiong Ham, pendiri pabrik gula di Semarang, dimana koleksi beliau inilah yang banyak dipajang di hotel ini. Hotel ini juga memiliki dua restoran dengan konsep interior yang berbeda, yaitu Restoran Melati yang berkonsep peranakan kontemporer dan SaigonSan yang bernuansa interior ruang seperti berada di dalam suatu bangunan candi batu HinduBuddha.

Pengunjung pada lokasi ini amat gemar untuk melakukan selfie berdampingan dengan artefak bersejarah yang dianggapnya menarik, unik secara visual, atau memiliki latar belakang kisah yang menarik. Kecenderungan pengunjung juga dapat terekam saat melakukan selfie di area Restoran Melati, biasanya pengunjung lebih memilih selfie berkelompok dibandingkan dengan selfie pribadi, dengan jumlah pengambilan gambar yang tidak terlalu banyak, rata-rata 2-3 kali pengambilan gambar. Namun saat berada di Restoran SaigonSan, pengunjung ingin melakukan selfie pribadi, dengan mencoba berbagai sudut dan pose yang dianggap menarik sehingga satu individu bisa melakukan lebih dari 3 kali pengambilan gambar di area ini. Hal ini terjadi dikarenakan pengunjung menganggap konsep dan suasana ruang di area SaigonSan lebih menarik dan unik apabila dibandingkan dengan Restoran Melati.

Melalui hasil analisa data dan observasi diatas, diketahui bahwa fenomena swafoto mempengaruhi kedua kelompok responden dengan model yang berbeda. Pada kelompok profesional designer, fenomena swafoto telah membuat kelompok ini mempertimbangkan suatu proyek perancangan ruang publik komersial yang dapat mengakomodasi kebutuhan swafoto generasi muda, dimana aplikasinya dapat berupa konsep keseluruhan perancangan ruang interior yang didesain dengan tema-tema khusus, ataupun hanya berupa sebuah lokasi pada salah satu sudut ruangan yang di khususkan untuk swafoto pengunjung. Dalam penerapan konsep perancangan menyeluruh, biasanya kelompok profesional desainer ini menggunakan konsep-konsep yang tematik, perancangan elemen-elemen estetika asesoris interior sebagai point of interest pengunjung. Dan munculnya awareness terhadap visual point of interest yang lebih menonjolkan gambar-gambar estetika visual dengan skala yang besar (mural), seperti yang terdapat di Kawasan Wisata Kayutangan.

Sementara pada kelompok kedua, fenomena swafoto membuat pengguna ruang lebih dapat memilih beragam area swafoto yang dianggap menarik secara visual menurut pengunjung. Pengunjung yang melakukan swafoto biasanya melakukan trial and error dalam pengambilan gambar, dengan mencoba-coba berbagai sudut pengambilan gambar dan area yang berbeda, sehingga pengunjung yang memilih satu area swafoto dapat melakukan berkali-kali pengambilan gambar untuk menemukan komposisi visual gambar yang tepat menurut mereka. Pada studi kasus Golden Heritage, pengunjung tidak hanya mengabadikan estetika visual ruangan, namun juga visual dari komposisi makanan yang disajikan. Motivasi perilaku seperti itu berdasarkan teori Van Hose (dalam Okabe \& Ito, 2005) dapat dimasukkan kedalam kelompok motivasi presentasi diri, dimana pengunjung ingin memberikan gambaran citra diri yang baik kepada pengikutnya di media sosial. Bagan konstruksi analisa dapat dilihat pada gambar 4. 


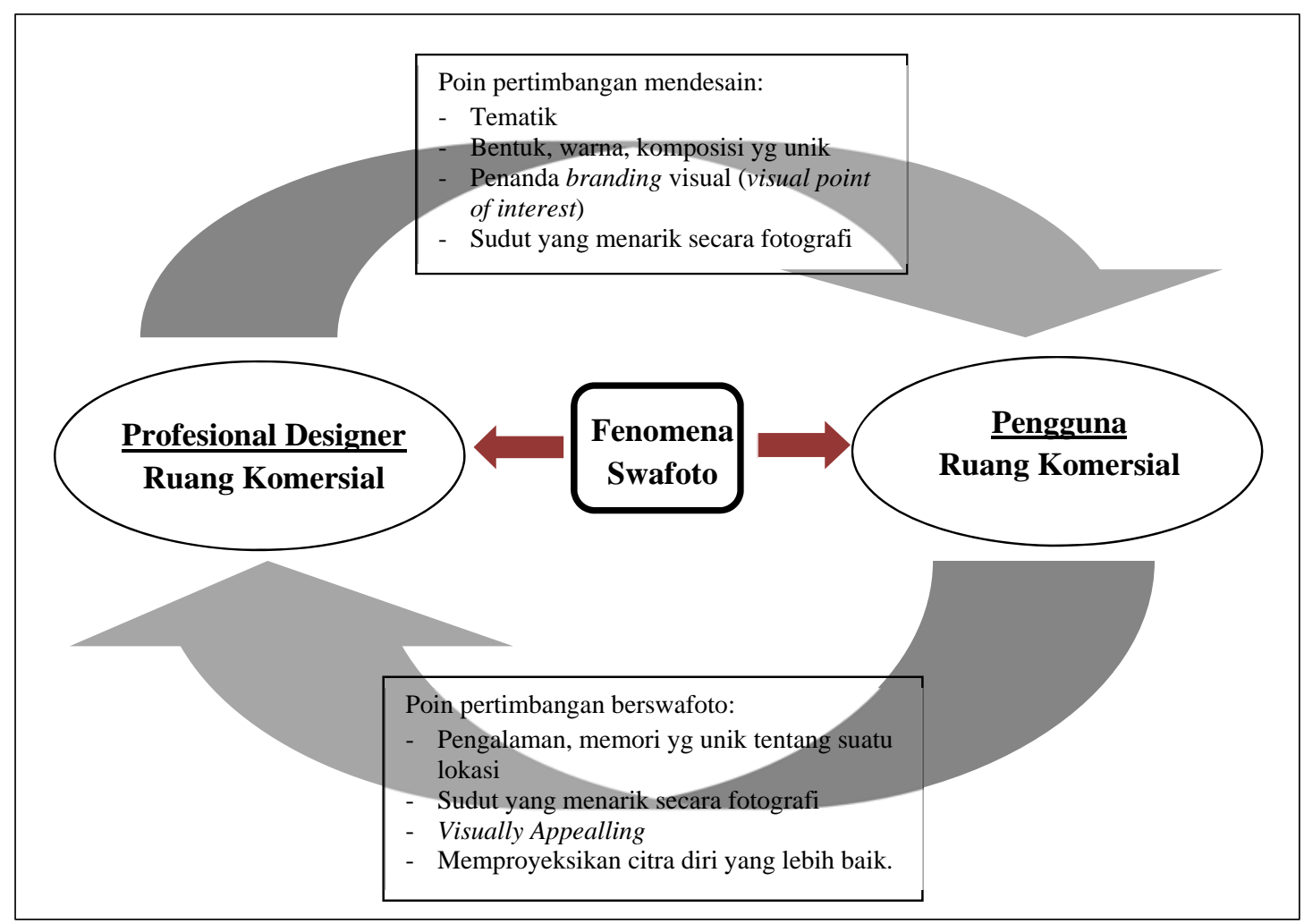

Gambar 4. Konstruksi Sebab-Akibat Fenomena Swafoto pada Pengunjung dan Perancang Sumber: konstruksi pribadi (2019)

Pada ketiga obyek studi kasus diatas, kebanyakan mengusung konsep kontemporer dan populer retro (Kampung Wisata Heritage Kayutangan \& Golden Heritage) sementara Hotel Tugu memiliki unsur konsep visual klasik kolonial dan masa lampau. Hal ini memberikan indikasi bahwa unsur klasik dan retro masih menjadi trend yang menarik di kalangan generasi muda.

\section{KESIMPULAN}

Berdasarkan hasil analisa pembahasan sebelumnya, dapat diambil kesimpulan bahwa fenomena swafoto menciptakan keterkaitan secara langsung terhadap pengambilan keputusan desainer interior/arsitektur dalam merancang ruang komersial publik. Sebagian besar desainer ruang interior telah dan akan merancang ruang dengan mempertimbangkan keunikan dalam tema, penanda visual branding, dan sudut serta obyek yang mampu menciptakan estetika visual yang bagus saat menjadi obyek fotografi pengunjung, dengan tujuan untuk menarik minat masyarakat generasi muda berkunjung untuk berswafoto. Pemanfaatan fenomena swafoto dengan menjadikannya sebagai strategi branding awareness dan marketing kepada masyarakat luas di platform media sosial adalah sesuatu hal yang telah menjadi kelaziman pada masa ini. Hal tersebut secara timbal-balik memberikan pengaruh juga pada generasi muda (40 tahun kebawah) terhadap naiknya visual awareness estetika ruang maupun estetika visual yang terdapat di suatu lokasi wisata ataupun lingkungan sekelilingnya. Kondisi ini didukung oleh perkembangan teknologi kamera gawai yang amatlah mudah penggunaannya dalam melakukan pengambilan gambar, pemilihan gambar, dan unggah foto, apabila dibandingkan dengan 
kamera konvensional yang besar, berat, dan memerlukan transfer data terlebih dahulu untuk dapat diunggah ke media sosial.

Hal ini di masa mendatang tentu saja akan lebih memperdalam akar budaya visual dalam komunikasi simbolis masyarakat, terutama generasi muda. Kondisi ini perlu dimanfaatkan dengan baik oleh para desainer dari segala lini: baik interior, arsitektur, grafis, hingga produk, untuk dapat memberikan desain yang tidak hanya menarik secara visual, namun juga mampu memberikan pemahaman budaya, lingkungan, dan estetika yang benar kepada masyarakat. Diharapkan penelitian ini dapat menjadi landasan terhadap penelitian-penelitian selanjutnya, terkait tingkat karakteristik ruang yang diminati masyarakat untuk ber-swafoto, ataupun elemen-elemen ruang apa saja berpengaruh terhadap keberhasilan suatu area untuk menjadi destinasi wisata swafoto masyarakat. Penelitian ini juga dapat dilanjutkan dengan menambahkan data visual ruang yang lebih banyak lagi sehingga karakteristik estetika visual yang diminati oleh pengunjung dapat terkategorikan dengan lebih baik lagi.

\section{DAFTAR PUSTAKA}

Ajeng, D., \& Oktavia, R. (2018). Motif Penggunaan Swafoto Sebagai Bentuk Eksistansi Diri Dalam Akun Instagram (Studi Deskriptif Kualitiatif Penggunaan Swafoto Dalam Media Sosial Instagram Sebagai Bentuk Eksistensi Diri Pada Mahasiswa Universitas 17 Agustus 1945 Surabaya). Representement, 1-9. Retrieved from http://jurnal.untagsby.ac.id/index.php/representamen/article/view/1420.

Ardiyanti, H., Hadyanto, D. T., Krislamawaty, D., \& Irwansyah, D. (2018). Swafoto: Sebuah Pendekatan Teori Manajemen Privasi Komunikasi. Aspirasi: Jurnal Masalah-Masalah Sosial, 9(1), 101-117. https://doi.org/https://doi.org/10.22212/aspirasi.v7i1.1084.

Cahyanti, M. M., \& Anjaningrum, W. D. (2017). Meningkatkan niat berkunjung pada generasi muda melalui citra destinasi dan daya tarik kampung wisata. JIBEKA, 11(1), 35-41. Retrieved from https://lp2m.asia.ac.id/wp-content/uploads/2017/09/5.-JURNALMEGA-M-WIDIYA-D-JIBEKA-VOL-11-NO-1-AGUSTUS-2017.pdf.

Hidalgo, M. C., \& Hernández, B. (2001). Place attachment: Conceptual and empirical questions. Journal of Environmental Psychology. https://doi.org/10.1006/jevp.2001.0221.

Ismanto, I. (2018). BUDAYA SELFIE MASYARAKAT URBAN: Kajian Estetika Fotografi, Cyber Culture, dan Semiotika Visual. Rekam, 14(1), 67-76. Retrieved from http://journal.isi.ac.id/index.php/rekam/article/view/2138.

Kavitha Bhuvaneswari, S. R. (2016). Impact of Social Media on Millennials-A Conceptual Study. Apeejay-Journal of Management Sciences and Technology, 4(1). Retrieved from https://www.eventbrite.com/blog/academy/millennials-fueling-experience-economy/.

Kurniawan, E. (2018). Sensasi Menyeruput dengan Suasana Pabrik Kopi di Golden Heritage Koffie. Retrieved May 23, 2019, from https://malangtoday.net/todaylicious/suasanapabrik-kopi-golden-heritage-koffie/\#.

Mecca, A. (2019). Foto selfie sebagai ekspresi femininitas perempuan. CAPTURE, 10(2), 119. Retrieved from https://jurnal.isi-ska.ac.id/index.php/capture/article/view/2246.

Najib, M. A., Sugiarto, A., \& Erawati, E. (2018). Swafoto Narsistik dan Harga Diri Remaja. INSAN Jurnal Psikologi Dan Kesehatan Mental, 2(2). https://doi.org/10.20473/jpkm.v2i22017.103-110.

Okabe, D., \& Ito, M. (2005). Everyday Contexts of Camera Phone Use: Steps Towards Technosocial Ethnographic Frameworks. Höflich, Joachim \& Hartmann, Maren Eds. 
Mobile Communication in Everyday Life: An Ethnographic View. Retrieved from http://www.itofisher.com/mito/archives/camphones.okabeito.pdf.

Tanasa, E. J. (2015). Studi Kualitatif Motif \& Kepuasan Penggunaan Foto Selfie Dalam Akun Instagram. Retrieved from https://digilib.uns.ac.id/dokumen/detail/46711/StudiKualitatif-Motif-Kepuasan-Penggunaan-Foto-Selfie-Dalam-Akun-Instagram.

Wanagiri, D. I. D., Widyastuti, N. K., Luh, N., Prawitha, C., \& Suyasa, S. (2018). Wisata Swafoto Sebagai Daya Tarik Wisata. Sintesa, (November), 363-370. Retrieved from https://jurnal.undhirabali.ac.id/index.php/sintesa/article/view/504.

Yuniarso, A., Wiyana, T., Zulkarnain, A., \& Khrisnanto, I. (2018). Travel Selfie dan Destination Image: Studi Kasus Taman Bunga Jalan Jalur Lingkar Selatan. In National Conference of Creative Industry: Sustainable Tourism Industry for Economic Development (pp. 5-6). Retrieved from https://journal.ubm.ac.id/index.php/ncci/article/view/1203. 